Jurnal Natur Indonesia 14(1), Oktober 2011: 14-18

ISSN 1410-9379, Keputusan Akreditasi No 65a/DIKTI/Kep./2008

\title{
Penggunaan Zeolit sebagai Pendegradasi Senyawa Permetrin dengan Metoda Fotolisis
}

\author{
Zilfa $^{*)}$, Hamzar Suyani, Safni dan Novesar Jamarun \\ Laboratorium Kimia Analisis Terapan, Jurusan Kimia, Fakultas Matematikan dan Ilmu Pengetahuan Alam, \\ Universitas Andalas, Padang 25163
}

Diterima 12-05-2010Ｄisetujui 04-10-2011

\begin{abstract}
The research about the degradation of permethryn compound has been done by photolysis method using natural zeolyte as catalyst. Permethryn is one syntetic pyretroid pesticides that low toxicity for mammals but it is high toxicity for fishs, insects and water microorganisms. Zeolyte is aluminosilicate minerals that can be used for degradation of permethryn. Percentage degradation of permethryn is lower without zeolyte than using zeolyte as catalyst by photolysis method. $20 \mathrm{mg} / \mathrm{l}$ permethryn solution could be degraded $5.40 \%$ after 120 minutes irradiation, while by adding $0.20 \mathrm{~g}$ natural zeolyte, permethryn could be degraded $69.70 \%$.
\end{abstract}

Keywords: degradation, permethryn, photolysis, zeolyte

\section{PENDAHULUAN}

Zeolit merupakan senyawa aluminosilikat terdapat di Indonesia dalam jumlah besar dengan bentuk hampir murni dan harga murah. Zeolit telah digunakan untuk pengolahan limbah industri dan nuklir (PTLR \& Batan 2007). Dilihat dari bentuk strukturnya, zeolit merupakan senyawa yang mempunyai pori teratur, luas permukaan yang besar berbentuk tetrahedral, selektifitas yang tinggi (Bahadur 1984). Oleh karena itu maka zeolit banyak digunakan sebagai penukar ion, penyerap, penyaring molekul dan katalis (Zilfa et al. 2009; Setiawan \& Handoko 1996). Sebagai katalis zeolit telah dapat digunakan untuk degradasi senyawa organik. Selain itu zeolit juga dapat digunakan sebagai pendukung katalis lainnya seperti $\mathrm{TiO}_{2}$ yang membentuk ( $\mathrm{TiO} /$ /Zeolit) untuk degradasi senyawa organik secara fotokatalis dan sonokatalis (Chun et al. 1998).

Berdasarkan hal di atas zeolit dapat sebagai pembantu degradasi senyawa organik maka zeolit juga dapat sebagai degradasi pestisida. Pestisida merupakan salah satu hasil teknologi modern yang mempunyai peranan penting dalam meningkatkan kesejahteraan rakyat. Pestisida telah digunakan dalam usaha meningkatkan produksi bahan pangan, melindungi tanaman dari hama penyakit, untuk melindungi hutan dan juga digunakan untuk memperbaiki kualitas tempat-tempat rekreasi (Zilfa et al. 2009; Guyer \& Ince 2003). Tidak dapat dipungkiri bahwa dari pengamatan para ahli dan pengalaman hidup sehari-hari hal tersebut telah terbukti dengan positif. Namun di lain pihak, meskipun pestisida telah memberikan nilai positif, pengaruh negatif berupa efek samping keracunan dan pencemaran lingkungan juga terjadi (Lutnicka et al. 1999; Riza 1994 ).

Salah satu jenis pestisida yang sering digunakan oleh petani karena murah dan mudah didapatkan adalah permetrin. Permetrin adalah suatu piretroid sintetik yang telah digunakan sebagai pembasmi serangga yang efektif. Permetrin mempunyai sifat tidak berbau, dan dapat membasmi serangga apabila sudah berkontak dengan serangga tersebut. (Riza 1994; Garcia et al. 2002).

Pengolahan limbah pestisida secara konvensional telah dilakukan yaitu dengan karbon aktif, lumpur atau sludge lalu dibakar, namun kurang efektif karena struktur senyawa dalam limbah mengandung satu atau beberapa buah cincin benzene. Oleh karena pembakaran sludge mengakibatkan terbentuknya senyawa klorooksida dan karbon monoksida. (Garcia et al. 2002; Wang \& Budey 2001; Safni et al. 2008).
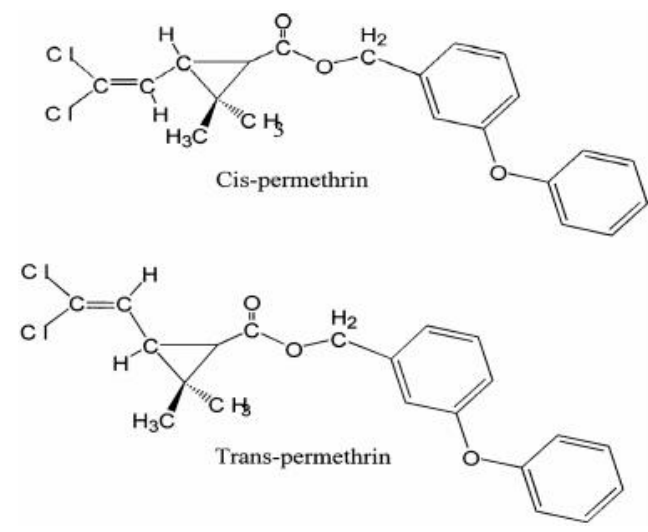

Gambar 1 Struktur senyawa permetrin 
Adapun alternatif lain untuk penanggulangan limbah pestisida senyawa permetrin telah dilakukan penelitian degradasi secara sonolisis dan ternyata dapat mencapai 70\%, (Zilfa et al. 2009; Safni et al. 2008). Metoda lain yang lebih efektif dapat dilakukan adalah metoda fotolisis. Fotolisis adalah bahagian dari proses oksidasi lanjut (AOPS; Advanced Oxydation Process) dan fotokatalis merupakan suatu proses yang dibantu dengan adanya cahaya dan material katalis. Polutan organik dapat dioksidasi menjadi $\mathrm{CO}_{2}$ dan $\mathrm{H}_{2} \mathrm{O}$ kebanyakan cahaya Ultraviolet (Safni et al. 2008). Salah satu katalis yang dapat dipakai adalah zeolit. Struktur zeolit yang berpori dengan molekul air di dalamnya, melalui pemanasan menyebabkan molekul air mudah lepas sehingga menjadikan zeolit sebagai adsorben penyerap molekul, penukar ion dan katalisator. Disini dengan adsorpsifitas dari polutan oleh zeolit fotokatalis dapat menaikkan efisiensi dekomposisi, dimana sesuai dengan Langmuer-Hinhelwood yang mengindikasikan adsorpsi berperan dalam reaksi oksidasi (Garcia et al. 2002; Chun et al. 1998; Hiskia et al. 2001 ).

\section{BAHANDANMETODE}

Alat-alat yang digunakan adalah Spektrofotometer UVVIS (S.1000 Secoman, Sarceles Prancis), kotak irradiasi yang dilengkapi dengan lampu UV 10 watt dengan $\lambda=365 \mathrm{~nm}$ (Germichal CE G 13 Base 8FCI11004), sentrifus dengan kecepatan $6000 \mathrm{rpm}$, (Profuge Model PRF 6Kp, Korea), magnetic stirer (SRS 116 AA Advanted) sebagai pengaduk.

Bahan yang digunakan dalam penelitian ini adalah Ambush 2 EC dengan bahan aktif permetrin dengan konsentrasi 96,1\%, asetonitril 99,5\% Proanalysis dari Merk KgaA, 64271 Damstadt, Germany. Zeolit berasal dari Tasikmalaya Bandung.

Prosedur. Penentuan serapan senyawa permetrin dilakukan dengan membuat variasi konsentrasi larutan sebagai berikut yaitu $0 ; 10 ; 20 ; 30 ; 40 ; 50$ mg/l dan diukur absorban dengan spektrofotometer UV-VIS. Larutan permetrin dengan konsentrasi $20 \mathrm{mg} / \mathrm{l}$ dimasukkan ke dalam lima buah labu ukur $25 \mathrm{ml}$ dengan volume masing-masing $20 \mathrm{ml}$. Setelah itu masing-masingnya difotolisis dengan memakai lampu UV selama waktu $0 ; 30 ; 60 ; 120 ; 180$; 240 menit. Kemudian larutan yang telah difotolisis diukur absorbannya dengan spektrofotometer UV-VIS.

Selanjutnya dilakukan fotolisis dengan penambahan zeolit $0 ; 0,05 ; 0,10 ; 0,15 ; 0,20 ; 0,25 \mathrm{~g}$ ke dalam masing-masing erlemeyer $25 \mathrm{ml}$ yang telah berisi $20 \mathrm{ml}$ permetrin $20 \mathrm{mg} / \mathrm{l}$. Setelah itu disentrifus selama 15 menit dan filtratnya diambil.
Lalu diukur absorban dengan spektrofotometer UV-VIS. Kemudian dilanjutkan degradasi pengaruh waktu setelah penambahan zeolit yaitu $20 \mathrm{ml}$ permetrin $20 \mathrm{mg} / \mathrm{l}$ dimasukkan ke dalam enam erlemeyer lalu difotolisis dengan $0,20 \mathrm{~g}$ zeolit pada waktu $0 ; 30 ; 60 ; 20 ; 180 ; 240$ menit. Setelah difotolisis disentrifus selama 15 menit dan filtratnya diambil serta diukur absorban dengan UV-VIS.

\section{HASIL DAN PEMBAHASAN}

Penentuan Serapan Maksimum Senyawa Permetrin.

Pengukuran serapan maksimum permetrin dilakukan pada daerah panjang gelombang 200-400 nm. Gambar 2 memperlihatkan dengan kenaikan konsentrasi didapatkan kenaikan absorban secara kontinyu pada panjang gelombang $272 \mathrm{~nm}$. Dengan ini dapat dikatakan bahwa senyawa permetrin menyerap sinar UV pada panjang gelombang $272 \mathrm{~nm}$. Untuk proses degradasi selanjutnya dilihat dari spektrum linier ini maka konsentrasi yang dipakai adalah $20 \mathrm{mg} / \mathrm{l}$, ini diasumsikan bahwa seandainya terdegradasi $100 \%$ masih terlihat absorban paling kecil et al. 2007).

\section{Pengaruh Waktu Iradiasi Terhadap Degradasi.}

Metoda fotolisis dalam proses kimianya menghasilkan radikal $\mathrm{OH}$ dalam larutan berair. Radikal $\mathrm{OH}$ tersebut yang akan menyerang senyawa organik untuk mengawali proses mineralisasi. Dimana proses pembentukan radikal adalah dari $\mathrm{H}_{2} \mathrm{O}+\mathrm{h}^{+} \rightarrow \mathrm{HO}+\mathrm{H}^{+}$. Hal ini terjadi karena proses degenerasi poto hole $\left(\mathrm{h}^{+}\right)$reaksi dapat terjadi dengan penyerapan molekul air sehingga dapat menghasilkan radikal $\mathrm{OH}$ (Arsac et al. 2007). Dari Gambar 3 dapat dilihat bahwa degradasi senyawa permetrin $20 \mathrm{mg} / \mathrm{l}$ sebanyak $20 \mathrm{ml}$ semakin lama waktu iradiasi semakin banyak jumlah radikal.OH yang berperan dalam mendegradasi senyawa permetrin. Waktu yang dianggap paling optimum untuk mendegradasi $20 \mathrm{mg} / \mathrm{l}$ permetrin sebanyak $20 \mathrm{ml}$ adalah pada 120 menit

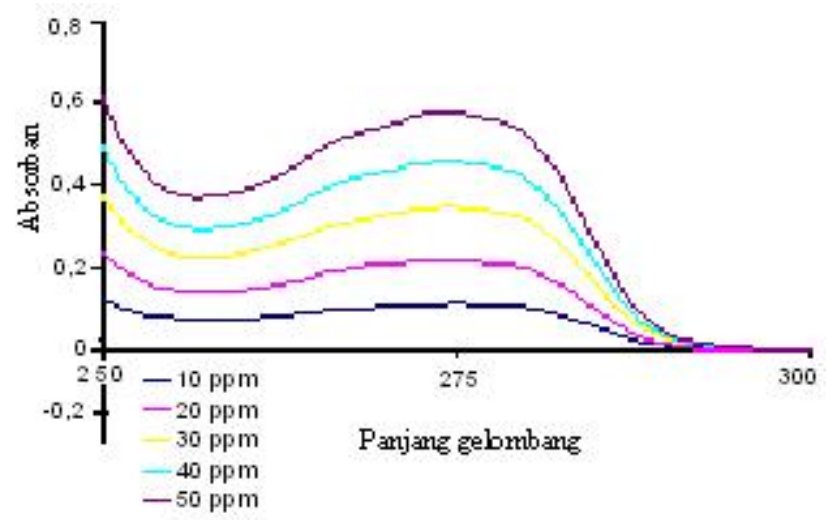

Gambar 2 Spektrum absorban senyawa permetrin dengan variasi konsentrasi dari bawah keatas 10, 20, 30, 40, dan $50 \mathrm{ppm}$ 
dengan persen degradasi 4,49\%. Penambahan waktu selanjutnya, kenaikan persen degradasi tidak begitu signifikan (Era et al. 2009).

Pengaruh Jumlah Zeolit Terhadap Degradasi. Adapun degradasi senyawa permetrin $20 \mathrm{mg} / \mathrm{l}$ sebanyak $20 \mathrm{ml}$ selama 120 menit secara fotolisis tanpa katalis menghasilkan degradasi yang belum sempurna, sehingga perlu dilakukan fotokatalisis yaitu dengan pemberian katalis. Katalis yang dipakai zeolit yang diharapkan degradasi semakin besar. Hasil degradasi dapat dilihat pada Gambar 4.

Fotolisis yang disertai dengan penggunaan katalis disebut fotokatalis. Pengaruh fotokatalis terhadap proses fototransformasi merupakan sinergis antara penyinaran dengan katalis. Pada metoda fotokatalisis, radikal $\mathrm{OH}$ dihasilkan melalui oksidasi permukaan anion hidroksida dan penyerapan molekul senyawa organik pada permukaan semi konduktor dengan adanya hole pada pita valensi (Hiskia et al. 2001).

Gambar 4 memperlihatkan penambahan katalis pada proses iradiasi senyawa permetrin $20 \mathrm{mg} / \mathrm{l}$ sebanyak $20 \mathrm{ml}$ selama 120 menit menunjukan penambahan persen degradasi berbanding lurus dengan penambahan jumlah

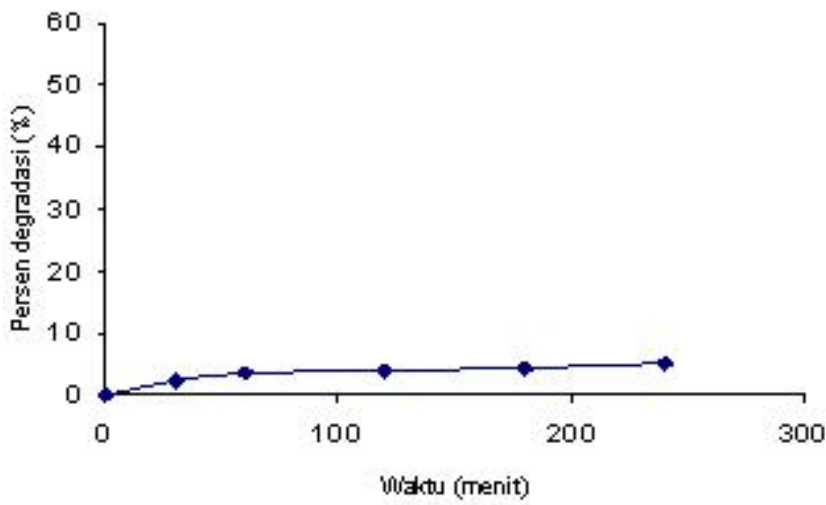

Gambar 3 Pengaruh waktu iradiasi terhadap degradasi $20 \mathrm{mg} / 1$ permetrin

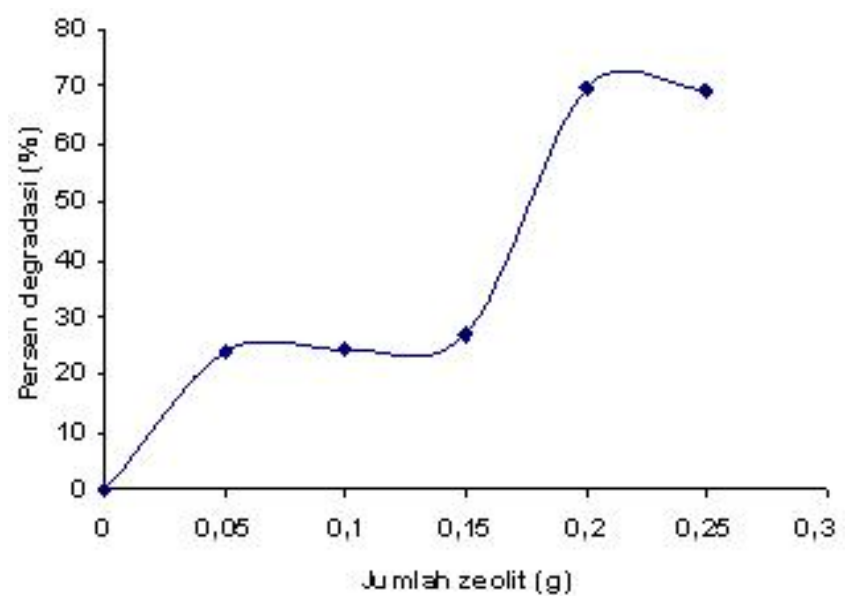

Gambar 4 Pengaruh jumlah zeolit terhadap degradasi $20 \mathrm{mg} / \mathrm{l}$ permetrin selama waktu iradiasi 120 menit katalis. Penambahan zeolit sebanyak 0,20 g mencapai 69,70\% selama waktu iradiasi 120 menit. Degradasi di bawah kondisi optimum pada (Gambar 4) persen degradasi kecil ini disebabkan karena belum sempurnanya degradasi. Di atas dari kondisi tersebut persen degradasi juga berkurang, hal ini disebabkan jumlah katalis yang diberikan lebih besar dari konsentrasi permetrin, sehingga terjadi kejenuhan larutan yang membuat larutan menjadi keruh. Keadaan ini akan mempersulit dalam pemisahan larutan dari katalis yang mengakibatkan besarnya absorban.

Pada proses iradiasi senyawa permetrin dengan penambahan zeolit menyebabkan absorbsi sinar UV oleh zeolit. Kemudian terjadi oksidasi yang diikuti perpindahan elektron pita valensi ke pita konduksi, dimana terbentuk pasangan elektron pada pita konduksi $\left(\mathrm{e}_{\mathrm{pk}}^{-}\right)$dan lubang positif pada pita valensi $\left(\mathrm{H}_{\mathrm{pv}}^{+}\right)$. Pencahayaan ultraviolet $(\lambda<400 \mathrm{~nm})$, mengakibatkan permukaan zeolit mempunyai kemampuan menginisiasi reaksi kimiawi (Lu et al. 1999; Korn et al. 2003; Safni et al. 2008).

Oleh karena zeolit merupakan aluminasilika yang terhidrasi dan bersifat asam, maka ion $\mathrm{H}^{+}$yang bereaksi dengan $\mathrm{O}^{2-}$ dapat meningkatkan jumlah $\mathrm{H}_{2} \mathrm{O}_{2}$. Dengan meningkatnya jumlah $\mathrm{H}_{2} \mathrm{O}_{2}$ maka jumlah radikal $\mathrm{OH}$ dan $\mathrm{OH}^{-}$ yang dihasilkan bertambah. Banyaknya $\mathrm{OH}^{-}$yang terbentuk akan meningkatkan jumlah radikal $\mathrm{OH}$ yang berperan dalam mendegradasi permetrin. Jadi terlihat bahwa dalam ketersediaan oksigen, substrat atau senyawa yang akan didegradasi tidak mengalami transfer muatan secara langsung tetapi melibatkan terbentuknya hidrogen peroksida lebih dahulu sebagai sumber radikal hidroksil (Safni et al. 2008; Era et al. 2008 ).

Pengaruh Waktu Iradisi Dengan Penambahan Zeolit

Terhadap Degradasi. Gambar 5 memperlihatkan pada penambahan 0,20 g zeolit, semakin lama waktu radiasi penambahan degradasi semakin banyak sehingga persen degradasi semakin besar. Disini waktu yang dianggap

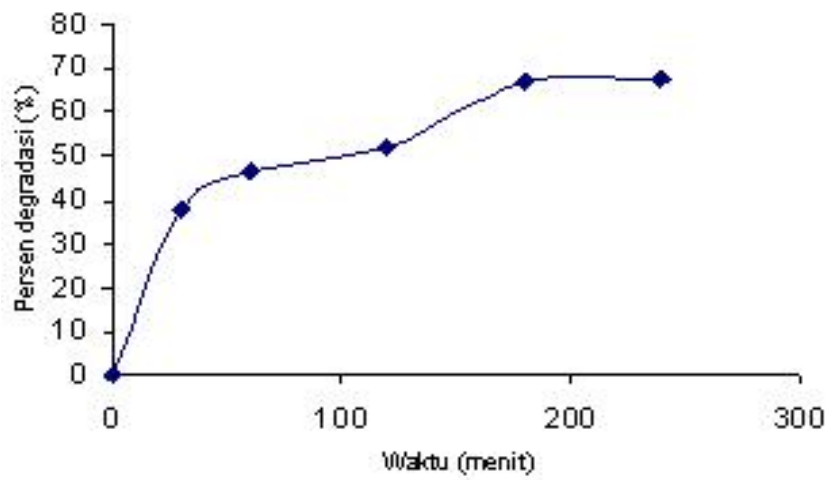

Gambar 5 Pengaruh waktu penyinaran setelah penambahan 0,20 g zeolit terhadap degradasi $20 \mathrm{mg} / 1$ permetrin 
optimum adalah selama 120 menit, sedangkan semakin bertambah waktu irradiasi penambahan persen degradasi tidak terlalu signifikan.

Zeolit dengan struktur kerangka mempunyai luas permukaan yang besar dan mempunyai saluran yang dapat digunakan sebagai penyaring ion molekul. Bila atom $\mathrm{Al}$ dinetralisir dengan ion polivalen dapat bersifat katalis, dimana sifat katalis ini disebabkan uni kation pada atom $\mathrm{Al}$ zeolit yang dapat dipertukarkan dengan ion $\mathrm{H}^{+}$dan aktif sebagai katalis reaksi. Zeolit bila disinari sinar UV permukaannya mempunyai kemampuan menginisiasi reaksi kimia. Ketika material difotolisis, material tersebut menyerap energi foton dan menyebabkan penyerapan dan kemudian tejadi oksidasi sehingga pembentukan radikal $\mathrm{OH}$, dimana radikal $\mathrm{OH}$ akan menyerang ikatan senyawa-senyawa organik yang berada dalam media air, sehingga senyawa tersebut dapat dirubah menjadi senyawa tidak beracun. Semakin lama proses penyinaran maka semakin banyak penyerapan dan semakin banyak terbentuk radikal $\mathrm{OH}$ sehingga persen degradasi semakin besar (Harjit 2005).

Pengaruh Waktu Penyinaran Tanpa dan dengan Penambahan Zeolit Terhadap Degradasi. Dilihat dari hasil degradasi senyawa permetrin secara fotolisis antara tanpa penambahan dan dengan penambahan zeolit pada waktu yang sama terlihat perbedaan yang besar dengan arti kata katalis zeolit sangat mempengaruhi proses iradiasi. Gambar 6 memperlihatkan perbedaan persentase degradasi yang sangat signifikan antara tanpa penambahan zeolit dan dengan penambahan zeolit. Dengan demikian zeolit dapat digunakan dan akan menghasilkan degradasi yang besar, efektif dan efisien. Oleh karena zeolit banyak terdapat di Indonesia dengan struktur hampir menyerupai yang murni dan harga murah maka zeolit dapat dikembangkan untuk pemanfaatan degradasi ini. Dari penelitian lain bahwa untuk meningkatkan degradasi yang lebih besar efektif dan efisien maka zeolit dapat disusupkan ke dalam $\mathrm{TiO}_{2}$ sehingga akan

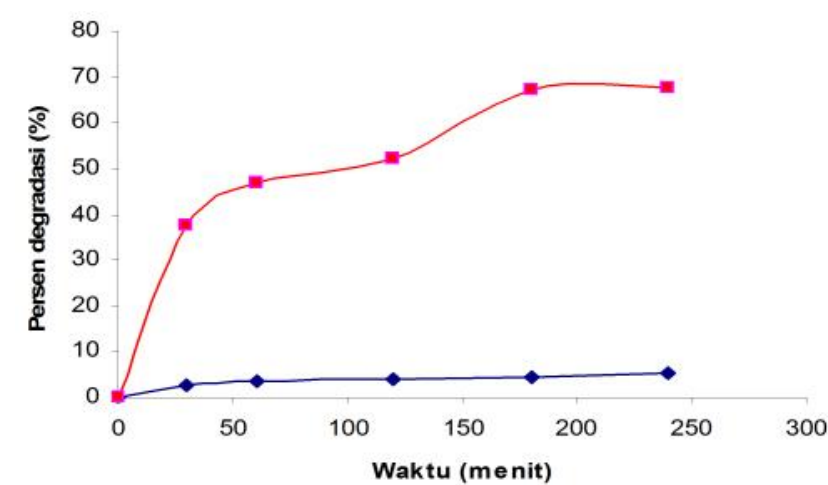

Gambar 6 Pengaruh Waktu iradiasi tanpa penambahan (f\&) dan dengan penambahan 0,2 g Zeolit $(\%)$ terhadap degradasi $20 \mathrm{mg} / \mathrm{l}$ permetrin dapat memperluas permukaan $\mathrm{TiO}_{2}$. Sebagai mana diketahui bahwa $\mathrm{TiO}_{2}$ merupakan katalis yang stabil, inert dan murni, akan tetapi jarang didapat di alam dan didapatkan secara industri dengan harga mahal. Untuk itu berdasarkan hal tersebut maka dengan menyusupkan zeolit ke dalam $\mathrm{TiO}_{2}$ maka akan menghasilkan degradasi yang lebih besar. (Zilfa et al. 2009; Chun et al. 1998).

\section{SIMPULAN}

Zeolit dapat digunakan untuk pendegradasi senyawa persmetrin secara fotolisis. Degradasi $20 \mathrm{mg} / \mathrm{l}$ permetrin dengan penambahan zeolit dapat dilakukan secara fotolisis dengan menggunakan lampu UV 10 watt $(\lambda=365 \mathrm{~nm})$. Degradasi $20 \mathrm{mg} / \mathrm{l}$ permetrin tanpa penambahan zeolit selama waktu iradiasi 120 menit menghasilkan persen degradasi sebanyak 5,40\%, sedangkan degradasi $20 \mathrm{mg} / \mathrm{l}$ permetrin selama waktu iradiasi 120 menit dengan penambahan $0,20 \mathrm{~g}$ zeolit mencapai sebanyak 69,70\%. Bahkan dengan jumlah zeolit yang sama tetapi waktu penyinaran lebih lama maka persen degradasi akan bertambah. Dari hasil degradasi zeolit dapat digunakan untuk degradasi permetrin tentu juga dapat digunakan untuk senyawa organik toksit lainnya.

\section{UCAPANTERIMAKASIH}

Kami sampaikan ucapan terima kasih kepada DIKTI dan PEMDA TK I Sumatera Barat yang telah memberikan bantuan dana untuk terlaksananya penelitian ini.

\section{DAFTAR PUSTAKA}

Arsac, F., Bianchi, D., Chovelen, M.J. \& Concen, P. 2007. Photocatalytic degradation of organic pollutants in water and in air. An Analytical Approach 43: 52-56.

Bahadur, K. 1984. Thermo catalytic of polythene using zeolite as catalyst to convert into high melting polythene wax. J.Def Sci 34(3): 293-299.

Chun,L.M., Chen, H.J., Cheng, T.K. \& Ming. 1998. Effect of adsorbents coated with titanium diokside on the photocatalytic degradation of propoxur, Chemstrophere 38(3): 617-627.

Era, Y., Safni \& Suyani, H. 2008. Degradasi senyawa paraguat dalam pestisida gramoxone (R) secara fotolisis dengan penambahan $\mathrm{TiO}_{2}$-Anatase. J. Ris. Kim 2(1): 94-100.

Garcia, E. Barbass, C. \& Corcia A. 2002. Validated HPLC Method for Quantifying Permethrin in Pharmaceutical Formulations. Universidat san Pablo-CEU,Madrid, Spain.

Guyer, T.G. \& Ince, H.N. 2003. Degradation and toxicity reduction of textile dyeestuff by ultrasound. Ultrasonic Sonochemistry 10: $235-240$.

Harjit, K. 2005. Zeolite Supported Transision Metal Catalyst to Enhance the Ozonation of Aquoes Phenol A Thesis Summitted in Fulfilment of the Requiretment for the Award of the degree of Master Engineering (Chemical) UTM.

Hiskia, A., Ecka, A., Troupis, A., Kokorakis, A. \& Hennig, H. 2001. Sonolytic, Photolytic, and photocatalytic decomposition of atrazine in the presence of polyoxometalates. J. Environ. Sci. Technology 35: 2358-2364.

Korn, M., Andrade, S. \& Borges, S.S. 2003. Reagent generation assisted by ultrasonic irradiation. Published on the web. 
Lu, C.M., Chen, N.J. \& Chen, T.K. 1999. Effect of adsorbents coated with titanium dioxide on the photocatalytic degradation of propoxur. Chromosphere 38: 617-627.

Lutnicka, H. Bogacka, B. \& Wolka, L. 1999. Degradation of pyrethroids in an aquatic ecosystem model. Accepted. 27 September 1999.

PTLR \& Batan. 2007. Potensi Zeolit untuk Mengolah Limbah Industri dan Radio Aktif Seminar, Kolokium ITB Bandung.

Riza, V.T. 1994. Ingatlah bahaya pestisida, bunga rapai residu pestisida dan alternatifnya. Jakarta: pesticide Action Network (PAN)

Safni, Maizatisna, Zulfarfarman \& Sakai, T. 2007. Degradas Zat Warna Naphtol blue Black secara Sonolisis dan Fotolisis dengan Penambahan $\mathrm{TiO}_{2}$-Anatase. J. Ris. Kim 1(1).
Safni, Loekman, U. \& Febrianti, F. 2008. Degradasi zat warna sudan I secara sonolisis dan foltolisis dengan penembahan $\mathrm{TiO}_{2}$ anatase. J.Ris. Kim I(2): 164-170.

Setiawan, D. \& Handoko, P. 1996. Preparasi Katalis Cr/Zeolit Melalui Modifikasi Zeolit Alam. Proceeding Jurusan Kimia FMIPA Universitas Jember, Indonesia.

Wang, N. \& Budey, L.W. 2001. Determination of Carbamate, Urea, and Thiourea pesticides and Herbicides in Water, Anal. Chemistry 72: 997-1006.

Zilfa, Safni, H., Suyani, N. \& Jamarun. 2009. Degradasi Senyawa Permetrin Dengan Menggunakan $\mathrm{TiO}_{2-}$ Anatase Dan Zeolit Alam Secara Sonolisis, J. Ris. Kim 2(2): 194-199. 